\title{
BISERICA SCIENTOLOGICĂ. O PERSPECTIVĂ MISIONAR-PASTORALĂ ASUPRA PROCEDEELOR DE VINDECARE
}

\author{
Gheorghe-Vlăduț RĂDULESCU*
}

\begin{abstract}
Scientological Church. A missionary-pastoral perspective on healing procedures ${ }^{\boldsymbol{I}}$. The great "discovery" of Scientology is that all human beings are, in fact, immortal tetans and possess an infinite creative potential. Tetans are not part of the physical universe, made up of energy, space, time, but have the ability to control it. They have lost contact with their origins and have remained in the bodies of mortal men as in a trap. Then they moved from one body to another, passing through successive lives without remembered their original state. Because of this amnesia, the tetanus has come to accept the illusion that they are nothing more than physical bodies. The most important practice in Scientology is called auditing, through which it identifies the engrams of the reactive mind of a prelude (a being possessed by the reactive mind) by observing its reaction to certain key words. This is done following meetings where the subjects undergo several exercises (training). The purpose of "auditing" is to remove the engrams so that individuals can relate their experiences directly and not through the reactive mind filter. The auditor's ultimate goal is to make the subject remember the first engram, received immediately after conception. In the higher stages of the audit, the individual becomes aware of his previous lives, lived as a tetanus in other bodies on this earth and even on other planets. The goal of dianetic therapy is to get the level of "light" (clear). "Luminaries" are those who have been cleansed from the memory of past traumatic experiences and, therefore, have more success in daily life, are healthier and have more communication skills. Because of this, dianetics has also been called
\end{abstract}

* PhD Student, Faculty of Orthodox Teology „Justinian Patriarch”, at University of Bucharest, Bucharest, Romania.

${ }^{1}$ Studiu realizat sub îndrumarea Pr. Conf. Univ. Dr. Radu Petre Mureşan, care şi-a exprimat acordul pentru publicarea acestuia. 
"applied theoretical psychology". The purpose of Scientology therapy is for the individual to become aware of the tetanus that lives in him. Achieving these goals is accomplished through practices that are characteristic of Scientology: auditing and training, purification, monitoring.

Keywords: Scientology, tetans, engrams, auditing, dianetic.

\section{Introducere}

Editura Freedom Publishing din Los Angeles, încă din anii 1970, a publicat broşuri în cadrul cărora cercetători din domeniul spiritualităţii comparate, al istoriei religiilor, al sociologiei şi al teologiei comparative a religiilor își expuneau cercetările ce aveau legătură cu caracterul religios al Scientologiei. În cadrul acestor rapoarte ${ }^{2}$ se poate identifica o elaborare a lucrărilor după un tipic uniformizat: autorul începe sau finalizează prin a-şi prezenta titlurile academice deținute şi opera redactată, prezintă definiţiile de tip sociologic ale religiilor şi arată că Scientologia dă dovadă de aceleaşi caracteristici ce îi permit să fie identificată ca religie: o doctrină; un cult; o instituţionalizare ierarhizată $\breve{3}^{3}$.

Grupurile cu caracter religios se folosesc uneori de studiile unor cercetători consacraţi, deoarece prin ele isși pot conferi un plus de legitimitate credinţelor şi practicilor lor de natură spirituală, mai ales în cazul unor grupări controversate, precum Scientologia. Studiile utilizate sunt numai o parte a rapoartelor de activitate ștințifică care au fost elaborate la cererea Bisericii Scientologice. Acest fapt îl recunosc o bună parte a autorilor ${ }^{4}$.

Ei nu se limitează numai la apreciere ştiinţifică, ci se folosesc de concluziile articolelor lor pentru promovarea cauzei Scientologiei în cadrul societății contemporane ${ }^{5}$. Publicațiile lor devin lucrări de tip

${ }^{2}$ Gerhardus Cornelis OosthuIzen, Philosophy, Religions and Church, South Africa, Edit. University of Durban-WestVille Natal, 1977, p. 12.

${ }^{3}$ Frank. K. FlinN, The Marks of Religion, Washington University St. Louis, Missouri, U.S.A., 1994, p. 7.

4 Darrol M. BRYANT, Scientology - A New Religion, Renison College, University of Waterloo, Waterloo, Ontario, Canada, 1999, p. 7.

5 Per-Arne Berglie, Scientology a Comparison with Religions of the East and West, University of Stockholm, Stockholm, Sweden, 1996, p. 9. 
apologetic, în momentul în care se invocă pretinse asemănări între etica scientologică şi doctrina creştină sau învăţăturile religiilor orientale. În acest mod se prezintă faptul că toate religiile tradiționale, inclusiv creştinismul, şi-au cristalizat doctrina şi practicile după o lungă perioadă de timp, fiind astfel nedrept să solicităm Scientologiei să aibă criteriile unei religii închegate imediat după „naşterea” sa. Se afirmă că s-ar putea constata asemănări între Crezul Creştin şi cel al Bisericii Scientologice sau că se poate dovedi o paralelă între practica denumită ,,auditing” şi Taina Spovedaniei, a Maslului şi a Euharistiei, deoarece respectiva practică ar avea efecte curățitoare de păcate, vindecătoare, dar și consacratoare $^{6}$.

Scientologia, în prezent, nu constituie încă subiect de preocupare al literaturii teologice, psihologice sau sociologice în România, chiar dacă lucrările lui La Fayette Ron Hubbard, întemeietorul sectei, au început să pătrundă pe teritoriul ţării traduse în română ${ }^{7}$. Studiile referitoare la Biserica Scientologică sunt, majoritatea, prezentări sumare, incluse în lucrările despre noile mişcări religioase care au apărut în România după $1989^{8}$.

O excepţie o constituie prezentarea părintelui Nicolae Achimescu, în lucrarea Noile Mişcări Religioase, sistematizată în patru părţi: istoricul şi organizarea Bisericii Scientologice, doctrina acesteia, metodele şi practicile ei, dar şi o evaluare din perspectivă ortodoxă. De asemenea, avem și lucrarea părintelui Marius Cloşcă, Ortodoxia şi noile mişcări religioase, unde Scientologia este prezentată alături de Ufolatrie, New Age şi Mişcarea Raeliană.

\section{Dianetica și Scientologia}

Pentru Hubbard, puterea minţii umane (mind), ocupă un loc central. El susţine faptul că mintea umană este structurată pe trei nivele interconectate: somatic, analitic, reactiv. Nivelul somatic este cel responsabil cu reglarea tuturor mecanismele de bază menite a susţine

\footnotetext{
${ }^{6}$ Frank. K. FlinN, The Marks..., p. 10.

${ }^{7}$ La Fayette Ron HubBard, Dianetica. Ştiinţa modernă a sănătăţii mentale, Bridge Publications/Los Angeles, New Era Publications/Copenhagen, 1999, p. 580.

${ }^{8}$ Constantin Cucıuc, Religii noi în România, Bucureşti, Edit. Gnosis, 1996, p. 146-147.
} 
viaţa organismului: funcții renale şi locomotorii. Mintea analitică reprezintă centrul de comandă, de aceea este infailibilă. Ea lucrează cu imaginația, cu percepția şi cu o „bancă de date” standard. Secțiunea analitică primeşte ca îndatorire informaţiile transmise de către simţuri, pe care acesta le va arhiva şi le va aranja în fişiere de stocare. Diviziunea analitică, în percepția lui Hubbard, se aseamănă cu un procesor infailibil ce nu poate provoca nici o eroare sau dezordine psihică sau fizică $\breve{9}^{9}$. In perioada de stres, această secțiune devine inoperantă şi diviziunea care câştigă preponderenţă în această situaţie este mintea reactivă. Aceasta este răspunzătoare pentru retrăirea unor evenimente traumatice din trecut, denumite „engrame”. Din momentul în care aceste „engrame” își fac apariția în mintea reactivă, ele prind rădăcini, iar persoana în cauză răspunde, într-o manieră reflexivă, la împrejurări care produc o asociere directă sau indirectă cu acele experienţe traumatice (sunete, emoții, mirosuri, senzaţii tactile, gusturi). Acestea inhibă exprimarea voinței libere a potenţialului uman al unei persoane adulte. De asemenea, engramele, sunt cele care împiedică individul să se adapteze corect lumii din jur printr-o manieră proprie şi naturală. În conformitate cu terminologia folosită de Hubbard, în acest caz, subiectul este ,aberat"10. Engramele devin astfel direct răspunzătoare pentru totalitatea tulburărilor psiho-somatice ale organismului viu, iar, în anumite cazuri, pot predispune chiar la îmbolnvirea fizică, ducând în cele din urmă la deces. Acestea nu numai că slăbesc imunitatea organismului, dar se pot perpetua prin divizare celulară. Din aceste considerente, engramele trebuiesc eliminate, pentru ca organismul uman să atingă și să rămână în starea de clear (pur, clar, luminat): „Clear-ul este ţelul terapiei dianetice...Orice persoană poate fi adusă la starea de clear, în afară de cazul unui nefericit căruia i-a fost îndepărtată o mare parte din creier sau care s-a născut cu o structură nervoasă grav deformată. Raţionalitatea poate fi studiată numai la o persoană adusă la starea de clear"11.

Tranziția de la dianetică la scientologie s-a realizat în anii 19521954, nefiind străină de ostilitățile cu care mediul ştiinţific şi medical

${ }^{9}$ La Fayette Ron HubBARd, Dianetica. Ştiinţa..., p. 57-58.

${ }^{10}$ Ibidem, p. 67.

11 Ibidem, p. 23. 
au primit teoriile lui Hubbard ${ }^{12}$. În textul broşurilor What is Scientology? se regăsește următoarea definiţie a grupării religioase: „Scientologia este studiul...cunoştinţelor despre om şi despre viaţă, lucru vital pentru fiecare persoană, dacă ea doreşte să fie fericită şi împlinită...Aplicarea principiilor Scientologiei poate îmbunătăţi încrederea unei persoane, inteligenţa, abilităţile sale...". Acest lucru se poate obţine fie prin căutările interiorizate ale rădăcinilor traumatice ale vieţilor anterioare, fie prin aducerea adeptului la conștientizarea că el are menirea de a ieși din propriul său corp pentru a i se descoperi faptul că acesta este o fiinţă individuală, care se află mai presus de spaţiu, timp, materie și energie ${ }^{13}$.

Adevărata „descoperire” a Scientologiei este că fiinţele umane sunt tetani nemuritori şi că ei deţin o putere de creație infinită. Tetanul nu este o parte a universului fizic, dar are potența de a-l controla după plac. El a pierdut contactul cu originile lui şi a rămas în corpul persoanei muritoare. Apoi, tetanii s-au mutat dintr-un trup fizic în altul, trecând prin vieţi succesive, fără a putea să-şi amintească de starea originară. Din pricina acestei amnezii, tetanul a ajuns să accepte această iluzie: că nu este altceva decât materie.

Aşadar, diferenţa dintre practica dianeticii şi religiozitatea scientologică apare mai clar. Cea dintâi se identifică ca fiind o psihoterapeutică prin intermediul căreia o persoană umană poate să ajungă la starea clear, în vreme ce a doua transcende viaţa pământească, având ca scop restituirea realităţii de tetan a adeptului, ce aduce cu ea şi creativitatea pe care o posedă. Părintele Achimescu susține faptul că învăţătura lui Hubbard, pentru mulți adepți, reprezintă „,o iluzie izvorâtă dintr-o lume a science fiction-ului, mai ales datorită faptului că doctrina promovată de ea este opera unui autor de science fiction" 14 .

Scientologia susţine și faptul că universul este pus în mişcare de impulsul supravieţuirii. Impulsul reprezintă aptitudinea unui organism, a unei persoane, a unui grup, a unui stat sau a unei rase, de rezolvare a problemelor de supravieţuire ${ }^{15}$.

12 Regis DericQuebourg, Religions de guerison, Paris, Edit. Cerf, 1988, p. 90-91.

13 Ibidem, p. 91-94.

${ }^{14}$ Nicolae ACHIMESCU, Noile Mişcări Religioase, Cluj-Napoca, Edit. Limes, 2002, p. 201.

${ }^{15}$ La Fayette Ron Hubbard, Dianetica. Ştiinţa..., p. 26. 
Acest impuls de supravieţuire la un om neiniţiat, „,neaberat”, se poate remarca pe opt niveluri, denumite „dinamici de supravieţuire”. Primele patru fac obiectul dianeticii, în timp ce următoarele patru au fost adăugate ulterior, după anul 1950, şi ţin de ethosul scientologic. Primul palier este cel al dinamicii de sine, acel reflex de supravieţuire, de căutare a plăcerii şi de evitare a durerii ${ }^{16}$. Cea de-a doua, dinamica de sex, este identificată ca impulsul ce asigură perpetuarea speciei; a treia este dinamica de grup, care guvernează domeniul vieţii sociale a indivizilor, în vreme ce a patra dinamică, cea a umanităţii, se preocupă de supravieţuirea umană ca specie. A cincea este dinamica vieţii, cea responsabilă cu mobilizarea unui individ să muncească, a şasea, dinamica universului fizic, a şaptea, dinamica gândirii, iar ultima este dinamica gândirii universale.

La finalul acestor niveluri de dinamică universală, Scientologia poate să admită existenţa lui Dumnezeu, ce posedă potenţial infinit, însă nu face dovada unei consecvențe în ceea ce priveşte doctrina sa despre divinitate. Hubbard afirma faptul că, după ani întregi de cercetări, investigaţiile sale au invalidat existenţa reală a unei Fiinţe Supreme, dar totuși, acesta nu excludea că viitorul poate să-l contrazică în această privinţă. Scientologia, nu pune accent pe natura lui Dumnezeu, ci se focusează pe posibilitatea organismelor umane de a fi sau de a se descoperi dumnezei ${ }^{17}$.

Există specialişti care acordă credit afirmaţiilor lui Hubbard, precum sociologul Roy Wallis, cel care a realizat unul dintre primele studii despre Biserica Scientologică ${ }^{18}$. Fiind bun cunoscător al spiritualităţilor orientale, Stephen Kent, arătă însă faptul că nu se poate face dovada unei influenţe de acest gen asupra dianeticii sau scientologiei, pentru că „Hubbard a demonstrat că nu avea decât cunoştinţe superficiale despre conceptele orientale pe care le menţiona ...Hubbard avea cunoştinţe superficiale despre hinduism, deşi afirmă că una din sursele sale este Veda". Kent îşi susţine afirmaţiile pe baza a numeroase exemple identificate de acesta în scrierile lui Hubbard ${ }^{19}$.

${ }^{16}$ Ibidem, p. 41.

${ }^{17}$ Ibidem, p. 51.

18 Jon ATACK, A piece of blue sky: Scientology and L. Ron Hubbard exposed, New York, Edit. Lyle Stuart, 1990, p. 14.

19 Stephen KENT, „Scientology's Relationship with eastern Religious Traditions”, în Journal of Contemporary Religion, 1/1996, p. 21-36. 
Afirmaţiile pe care Hubbard le prezintă despre pretinsele asemănări dintre doctrina scientologică şi religiile orientale au fost înaintate în perioada când acesta încerca să contracareze măsurile guvernamentale îndreptate împotriva lui pentru că practica medicina fără licenţă. În cadrul dianeticii, Hubbard afirmase faptul că mintea reactivă este singura răspunzătoare pentru producerea bolilor psiho-somatice şi că, prin utilizarea dianeticii, toate aceste afecțiuni se vindecă fără a fi nevoie de vreun alt tratament medicamentos sau intervenție chirurgicală: „Descărcaţi conţinutul băncii din mintea lui şi artrita dispare, miopia se ameliorează, boala de inimă scade, astmul dispare, stomacul funcţionează corect şi întreg catalogul de boli se ameliorează” sau „Clearii nu răcesc. Răceala vine de obicei dintr-un engram, care o cere, şi este confirmată de un mucus real prezent într-un alt engram" ${ }^{20}$. Din pricina acestor afirmaţii, Hubbard a fost acuzat de către colegiul medicilor de practicare ilegală a medicinei și farmaceuticii.

\section{Practicile dianeticii şi scientologiei în contextul terapeutic}

Scopul final al terapiei dianetice este de a-l ajuta pe individ în obţinerea nivelul de clear. „Luminaţii” sunt adepții care au fost vindecaţi de amintirile traumatice din trecut şi, datorită acestui lucru, sunt pasibili de mai mult succes în viaţa cotidiană, sunt mai fericiţi, mai sănătoşi şi dețin mai multe abilităţi comunicative. Datorită acestui fapt, dianetica a mai fost denumită şi ,,psihologie teoretică aplicată"21. Finalitatea terapiei de tip scientologic este aceea că individul devine conştient real de tetanul ce-1 locuieşte. Atingerea acestor țeluri se realizează prin intermediul unor practici specifice Scientologiei: ,auditing, training, purificare, monitorizare" 22 .

Cea mai importantă practică întâlnită în Scientologie poartă numele de auditing, prin intermediul acesteia identificându-se engramele, erorile din mintea reactivă a neiniţiatului preclar (fiinţă umană stăpânită de mentalul reactiv), prin observarea reacţiei acestuia la anumite cuvintecheie. Această acțiune se realizează prin nişte şedinţe în cadrul cărora

\footnotetext{
${ }^{20}$ La Fayette Ron HubBARd, Dianetica. Ştiinţa..., p. 119.

${ }^{21}$ Regis DericQuebourg, Religions..., p. 80.

${ }^{22}$ Nicolae ACHIMESCU, Noile Mişcări..., p. 210-217.
} 
subiectul este supus mai multor exerciţii (training). Spre exemplu, el este aşezat în faţa unui membru curățit, cerându-li-se să se observe reciproc privindu-se în ochi două ore, această practică numindu-se „,confruntare”. Un alt exerciţiu este punerea subiectului în faţa unor situații care provoacă furie, râs, melancolie sau alte reacţii de tip emoţional, pentru a-l putea observa cum se manifestă și care sunt stimulii la care el reacţionează din reflex, aceasta fiind cunoscută drept „,confruntarea cu hărţuire” sau bullbaiting ${ }^{23}$.

Scopul „auditing-ului” este eliminarea engramelor, încât individul să poată relata din experienţele sale direct, detaşându-se de filtrul minţii reactive. Ca ultim scop al auditorului, putem identifica intenția de a face pe cel preclar să retrăiască prima engramă, pe care a primit-o imediat după concepere. Această primă engramă se poate identifica drept o tentativă de avort care a adus rănire embrionului sau o stare de rău a mamei când era însărcinată. În nivelurile superioare ale practicii auditing, indivizii ajung să devină conştienţi de vieţile anterioare pe care le-au trăit ca tetani în alte corpuri, atât pe pământ, cât şi pe alte planete ${ }^{24}$. Spre exemplu, un om care este astmatic poate descoperi prin auditing faptul că a fost strangulat într-o viaţă anterioară. Individul care vrea să străbată acest drum eliberator este numit tetan operaţional (OT). El parcurge etapele iniţierii de la primul nivel OT I, până la ultimul nivel OT IX.

Tehnica auditing are două scopuri: de a convinge adeptul că el este un spirit atotputernic şi să-l conducă la starea de clear, prin ştergerea engramelor. Este interesant faptul că, în mentalitatea scientologică, indivizii nu ar fi responsabili ei înșişi pentru engramele lor, pentru că acestea sunt rezultatul unor momente traumatice. Doar în cazul în care oamenii vin în contact cu doctrina scientologică, aceștia devin pe deplin responsabili de a elibera tetanii care îi posedă. În clipa în care procesul auditing-ului avansează, practicantul susţine că dobândește puteri supranaturale fizice şi mentale. În broşurile Bisericii Scientologice, iniţiații povestesc că ajung să ştie dinainte că vor fi contactaţi de anumite

${ }^{23}$ DIDIER, De l'esperance à l'esclavage. Personnes victimes de sectes, travail effectué dans le cadre de la formation ESTS prèsenté par Hussy François, Genève, Edit. Neupriz Mireille, 1997, p. 10.

${ }^{24}$ Ibidem, p. 18. 
persoane înainte ca mobilul să sune sau chiar că au puterea de a vedea ce se petrece în apartamentul învecinat prin ziduri ${ }^{25}$.

În timp ce adeptul îşi „,clarifică” psihicul, el trebuie să-şi curețe şi trupul. Dacă luăm în considerare că, pentru Hubbard, boala are trei faze: predispoziţia, precipitarea şi perpetuarea, în acest caz, engrama primită în urma evenimentelor trumatice predispune la îmbolnăvirea unei părți din corp. De fiecare dată când este restimulată, egrama precipită sau declanșează boala. În cele din urmă, din pricina faptului că aceasta este continuu restimulată, boala se perpetuează chiar și după tratament. Curăţirea de engrame are ca rezultat creşterea și întreținerea forţei vitale, îmbunătățirea capacității de supravieţuire, conştientizarea puterii care rezidă în interior şi o performanță crescută în activitate. Din aceste considerente, Scientologia recurge la practicarea programelor de purificare, care au ca scop eliminarea din organism a toxinelor rezultate în urma utilizării medicamentelor sau a drogurilor, din ingerarea alimentelor modificat-genetic, din expunerea la radiaţiile nucleare, etc. Acestă practică constă în şedinţe de stimulare electrică, saună, însoţite de antrenamente fizice şi, desigur, de consumul de vitamine şi minerale. Adepții consumă regulat vitamine (pastile) dar şi un amestec bazat pe calciu cu magneziu, în scopul de a obţine „,o bună funcţionare psihologică"26.

O practică importantă în cadrul auditing-ului este monitorizarea indivizilor cu un dispozitiv, ,electrometru” (e-meter), inventat și patentat de Hubbard ${ }^{27}$. El identifică și raportează impulsurile corporale electrice transmise de piele. Iniţiatorii pun întrebări, apoi observă fluctuaţia aparatului, care arată, susţin auditorii, schimburile electrice din mintea reactivă datorate engramelor. Când este identificată încărcătura emoţională (engrama), neofitul este supus unor discuţii până când răspunsul emoţional nu se va mai produce la un nou stimul, fiind astfel curăţată şi eliminată ${ }^{28}$.

25 What is Scientology? The comprehensive reference on the world's fastest growing religion, Church of Scientology, Bridge Publications/ Los Angeles, New Era/Copenhagen, 1992, p. 307-309.

${ }^{26}$ L. Ron HubBARD, Tout sur les radiations, Copenhaga, Edit. Bridge Pubns, 1984, p. 96122.

${ }^{27}$ Regis DericQuebourg, Religions..., p. 94-96.

${ }^{28}$ DIDIER, De l'esperance à l'esclavage.., p. 81. 


\section{Concluzie}

Biserica Scientologică deține o doctrină care permite dialogul cu tradiția creștină ortodoxă, deoarece Scientologia susține existența reală a lumii spirituale și respectarea unui cod moral de către inițiați.

Ca punți de legătură, enumerăm: constituția dihotomică a omului, necesitatea curățirii spirituale și trupești, respectarea unui cod etic. Ideea adepților scientologi de necesitate a purificării tetanului și a trupului pentru reconcilierea lor cu rațiunea universală, poate fi explicată de tradiția răsăriteană ca fiind o reminisciență a conștiinței morale în oameni, sădită de Dumnezeu încă de la creația omului, conștiință ce mustră pe cel ce săvârșește păcatul și răsplătește pe cel ce face binele.

$\mathrm{Ca}$ aspect pozitiv, necesitatea curățirii prin discurs cu cel inițiat, post cu băuturi detoxifiante și regim alimentar, pentru a șterge engramele cu scopul de a dobândi sănătate trupească și spirituală, pot constitui obiectul unui dialog constructiv între Scientologie și dogmele Bisericii Ortodoxe, făcându-se paralele între această psiho-terapie și Tainele Spovedaniei și a Maslului.

Un alt aspect pozitiv îl constituie nevoia adepților scientologi de a fi membri inițiați ai grupului religios și de a se reconcilia cu tetanul care îl posedă și cu rațiunea universală, care poate face paralelă de dialog cu Taina Botezului și a Euharistiei.

Respectarea cu tărie a codului etic și monitorizarea periodică pentru a verifica starea spirituală și trupească a adepților, poate fi tot un aspect pozitiv, realizându-se punţi solide cu canoanele și dogmele bisericești pe care credincioșii trebuie să le respecte zilnic pentru a avea o viață morală.

$\mathrm{Ca}$ aspecte negative se pot identifica următoarele: accentul pus pe descoperirea dumnezeului din trup, încadrând astfel divinitatea în sfera impersonală sau chiar în inexistența ei; faptul că adepții sunt atinși de engrame din pricina altor evenimente sau persoane, ei fiind de fapt infailibili și puri, ducând astfel la o neasumare a realităţii păcatului, căutând mereu alți vinovați; problematica administrării suplimentelor alimentare, a vitaminelor și mineralelor, a băuturilor detoxifiante etc, negând importanța medicinii și a farmaceuticii, considerate că provoacă apariţia engramelor. 


\section{Referințe bibliografice:}

1. Cucıuc, Constantin, Religii noi în România, Bucureşti, Edit. Gnosis, 1996;

2. Bryant, Darrol M., Scientology - A New Religion, Renison College, University of Waterloo, Waterloo, Ontario, Canada, 1999;

3. DIDIER, De l'esperance à l'esclavage. Personnes victimes de sectes, travail effectué dans le cadre de la formation ESTS prèsenté par Hussy François, Edit. Neupriz Mireille, Genève, 1997;

4. FLINN, Frank. K., The Marks of Religion, Washington University St. Louis, Missouri, U.S.A., 1994;

5. Oosthuizen, Gerhardus Cornelis, Philosophy, Religions and Church, South Africa, Edit. University of Durban-WestVille Natal, 1977;

6. ATACK, Jon, A piece of blue sky: Scientology and L. Ron Hubbard exposed, New York, Edit. Lyle Stuart, 1990;

7. Hubbard, L. Ron, Tout sur les radiations, Copenhaga, Edit. Bridge Pubns, 1984;

8. HubBard, La Fayette Ron, Dianetica. Ştiinţa modernă a sănătăţii mentale, Bridge Publications/Los Angeles, New Era Publications/Copenhagen, 1999;

9. BERGLIE, Per-Arne, Scientology a Comparison with Religions of the East and West, University of Stockholm, Stockholm, Sweden, 1996;

10. ACHIMESCU, Nicolae, Noile Mişcări Religioase, Cluj-Napoca, Edit. Limes, 2002;

11. DericQuebourg, Regis, Religions de guerison, Paris, Edit. Cerf, 1988;

12. KENT, Stephen, „Scientology's Relationship with eastern Religious Traditions", în Journal of Contemporary Religion, 1/1996, p. 63-91;

13. What is Scientology? The comprehensive reference on the world's fastest growing religion, Church of Scientology, Bridge Publications/ Los Angeles, New Era/Copenhagen, 1992. 